\title{
Evolution of Frankia-Casuarinaceae interactions
}

\author{
Elisabeth Navarro a , Carole Rouvier ${ }^{\mathrm{b}}$, Philippe Normand ${ }^{\mathrm{b} *}$, \\ Anne Marie Domenach ${ }^{b}$, Pascal Simonet ${ }^{b}$, Yves Prin ${ }^{c}$ \\ ${ }^{\text {a }}$ Laboratoire de microbiologie, Centre ORSTOM in Nouméa, \\ BP A5 Nouméa cedex, New Caledonia \\ b Laboratoire d'écologie microbienne du sol, UMR CNRS 5557, Université Lyon I, \\ 43, boulevard du 11 novembre 1918, 69622 Villeurbanne cedex, France \\ ${ }^{\mathrm{c}}$ Laboratoire des symbioses tropicales et méditerranéennes, Campus de Baillarguet, \\ BP 5035, 34032 Montpellier cedex 1, France
}

\begin{abstract}
Nonisolated Frankia strains present in the root nodules of three of the four genera of the Casuarinaceae family (namely, Casuarina, Allocasuarina and Gymnostoma) have been characterised through polymerase chain reaction/restriction fragment length polymorphism (PCR/RFLP) analyses and sequencing of their nifD-nifK intergenic spacer (IGS). Analyses of the aligned sequences were used to deduce phylogenetic relations of these genes. Strains from Casuarina and Allocasuarina were found to be in the same cluster, while strains from Gymnostoma were closer to Elaeagnaceae strains. The relationships between IGS subgrouping and symbiotic (host spectrum) characteristics of the nonisolated strain confirmed the differences between Casuarina/Allocasuarina and Gymnostoma symbiosis. Genetic diversity among Casuarina and Allocasuarina microsymbionts seems to be host species-dependent. In contrast, no relation could be found between Gymnostoma microsymbionts and host species. The comparison between phylogenic analyses of the host plants and their microsymbionts suggests that the most coherent evolutionary scenario would be that an early split occurred in the evolution of Casuarinaceae, resulting into two distinct lines of descent. (C) Inra/Elsevier, Paris
\end{abstract}

diversity / Frankia / Casuarinaceae / coevolution

Résumé - Évolution des interactions Frankia-Casuarinaceae. En utilisant des analyses PCR/RFLP et le séquençage de l'intergène nifD-K, des souches non isolées de Frankia présentes dans les nodosités de trois des quatre genres constituant la famille des Casuarinacées (Casuarina, Allocasuarina and Gymnostoma) ont été caractérisées. L'analyse des séquences alignées a permis d'établir les relations phylogénétiques entre ces souches. Les souches infectives sur Casuarina et Allocasuarina appartiennent au

* Correspondence and reprints 
même groupe phylogénétique, alors que les souches infectives sur Gymnostoma sont regroupées avec les souches d'Elaeagnacées. Les relations entre le groupage moléculaire et les caractéristiques symbiotiques du micro-organisme (spectre d'hôte) confirment les différences entre les symbioses impliquant Casuarina/Allocasuarina et Gymnostoma. La diversité génétique des microsymbiotes de Casuarina et Allocasuarina semble être corrélée à l'espèce de la plante hôte. Au contraire, aucune relation n'a été trouvée entre le type de microsymbiotes de Gymnostoma et l'espèce végétale. La comparaison des arbres phylogénétiques des plantes hôtes et de leurs microsymbiotes suggère qu'une séparation précoce soit survenue dans l'évolution des Casuarinacées, entraînant l'existence de deux lignées de descendants. (c) Inra/Elsevier, Paris

diversité / Frankia / Casuarinacées / coévolution

\section{INTRODUCTION}

The actinomycete Frankia has established a nitrogen-fixing symbiosis with a wide range of dicotyledonous plants. This symbiosis is known to occur in more than 200 species of plants belonging to eight families (Betulaceae, Casuarinaceae, Myricaceae, Elaeagnaceae, Rhamnaceae, Rosaceae, Coriariaceae and Datiscaceae) (Benson and Silvester, 1993).

The Casuarinaceae family is composed of the four genera of tropical dicotyledonous plants Allocasuarina, Casuarina, Ceuthostoma and Gymnostoma, of which Gymnostoma is considered the most primitive (Johnson and Wilson, 1989). These plants are naturally confined to the Malaysian-Australian Melanesian region but some species, and particularly Casuarina equisetifolia, have been exported extensively to other tropical areas worldwide, to be used as windbreaks, to stabilise sand dunes or as a source of fuel wood (Diem et al., 1988; Diem and Dommergues, 1990). This is due in part to the nitrogen-fixing symbiosis that most of the 96 extant species from this family have established with the actinomycete Frankia permitting the plants to develop on poor soils.

No study has been carried out on the evolution of Frankia-Casuarinaceae relationships. Most of the genetic diversity work on Casuarinaceae infective strains has been done on strains isolated from Casuarina spp. and Allocasuarina spp. growing in areas where they are not native (Nazaret et al., 1991; Rouvier et al., 1992). Little is known about Gymnostoma microsymbionts, the only reports in the literature dealing with three successful isolations of Frankia strains in pure culture (Racette and Torrey, 1989; Savouré and Lim, 1991). Therefore, the phylogenetic relationships of Frankia strains infective on Casuarina, Allocasuarina and Gymnostoma genera from native areas have not been studied.

With this in mind, we studied the diversity of Casuarinaceae microsymbionts in northeastern Australia and New Caledonia, areas in the natural geographic range of the host plants. Using sequencing and polymerase chain reaction/restriction fragment length polymorphism (PCR/RFLP) analysis, we sought to compare Casuarinaceae microsymbionts and to determine the level of diversity among these strains and their relationships with host plant species. 


\section{MATERIALS AND METHODS}

\subsection{Nodules and bacterial strains}

Nodules and reference strains used are described in table $I$.

\subsection{DNA extraction from nodules}

After peeling off the superficial layers, nodule lobes were disinfected with $30 \% \mathrm{w} / \mathrm{v} \mathrm{H}_{2} \mathrm{O}_{2}$ for $5 \mathrm{~min}$, rinsed with sterile distilled water and kept at $-20^{\circ} \mathrm{C}$. One nodule lobe was crushed in $500 \mu \mathrm{L}$ of TCP buffer $(100 \mathrm{mM}$ Tris- $\mathrm{HCl}, \mathrm{pH} 8$, $1.4 \mathrm{M} \mathrm{NaCl}, 20 \mathrm{mM}$ EDTA, $2 \% \mathrm{w} / \mathrm{v}$ CTAB [Sigma, St Louis, MO, USA] and $3 \% \mathrm{w} / \mathrm{v}$ PVPP [Sigma], $\mathrm{pH} 8$ ). The mixture was incubated at $65^{\circ} \mathrm{C}$ for $1 \mathrm{~h}$ and centrifuged at $3000 \mathrm{~g}$ for $5 \mathrm{~min}\left(20^{\circ} \mathrm{C}\right)$. The supernatant was chloroformextracted and ethanol-precipitated. The DNA pellet was dissolved in $10 \mu \mathrm{L}$ of TE buffer ( $\mathrm{pH} 7.5)$.

\subsection{PCR amplification of nifD-nifK intergene}

For deoxyribonucleic acid (DNA) amplification of a region including the $3^{\prime}$ end of nifD, the intergenic spacer (IGS), and the beginning of nifK, primers FGPD807 (5'-CACTGCTACCGGTCGATGAA-3') (Jamann et al., 1993) and FGPK333' (5'-CCGGGCGAAGTGGCT-3') (Nalin et al., 1995) were used. PCR amplification was performed in $0.5 \mathrm{~mL}$ Eppendorf tubes in a total volume of $50 \mu \mathrm{L}$ containing: template DNA (approximately $0.1 \mu \mathrm{g}$ ), polymerase reaction buffer $\left(10 \mathrm{mM}\right.$ Tris- $\mathrm{HCl}, \mathrm{pH} 8.3,1.5 \mathrm{mM} \mathrm{MgCl}_{2}, 50 \mathrm{mM} \mathrm{KCl}, 0.01 \%$ $[\mathrm{w} / \mathrm{v}]$ gelatine, $20 \mu \mathrm{M}$ deoxynucleoside triphosphate [dNTP], $1 \mu \mathrm{M}$ each of the primers and 2.5 units of TaqI DNA polymerase [Gibco BRL, Gaithersburg, MD, USA]). DNA amplification was done in a thermocycler (Perkin Elmer, Norwalk, CT, USA) using the following programme: initial denaturation for $3 \mathrm{~min}$ at $95^{\circ} \mathrm{C}, 35$ cycles of denaturation $\left(30 \mathrm{~s}\right.$ at $\left.95^{\circ} \mathrm{C}\right)$, annealing $(30 \mathrm{~s}$ at $63^{\circ} \mathrm{C}$ ) and extension $\left(30 \mathrm{~s}\right.$ at $\left.72^{\circ} \mathrm{C}\right)$, and a final extension $\left(2 \mathrm{~min}\right.$ at $\left.72^{\circ} \mathrm{C}\right)$. PCR amplification of DNA was checked by agarose gel electrophoresis (2\% $\mathrm{w} / \mathrm{v}$ ) in TBE buffer with $5 \mu \mathrm{L}$ of PCR product. The gel was stained in an aqueous solution of $1 \mathrm{mg} \cdot \mathrm{L}^{-1}$ ethidium bromide and photographed with HP5 film with a 302-nm ultraviolet source.

\subsection{PCR amplification of 16S-23S intergene}

Amplifications of a part of the $16 \mathrm{~S}$ gene and the IGS were performed by using the standard conditions as described previously. Primers FGPS989e $\left(5^{\prime}\right.$-GGGGTCCTTAGGGGCT-3') (Bosco et al., 1992) and FGPL1973' (5'-ATCGGCTCGAGGTGCCAAGGGTC-3') (Navarro et al., 1992) were used for Gymnostoma DNA amplifications. Primers FGPS989ac (5'-GGGGTCCGTAAGGGTC-3') (Bosco et al., 1992) and FGPL132' (5'-CCGGGTTTCCCATTCGG-3') (Ponsonnet and Nesme, 1994) were used for Casuarina/Allocasuarina DNA amplifications. 


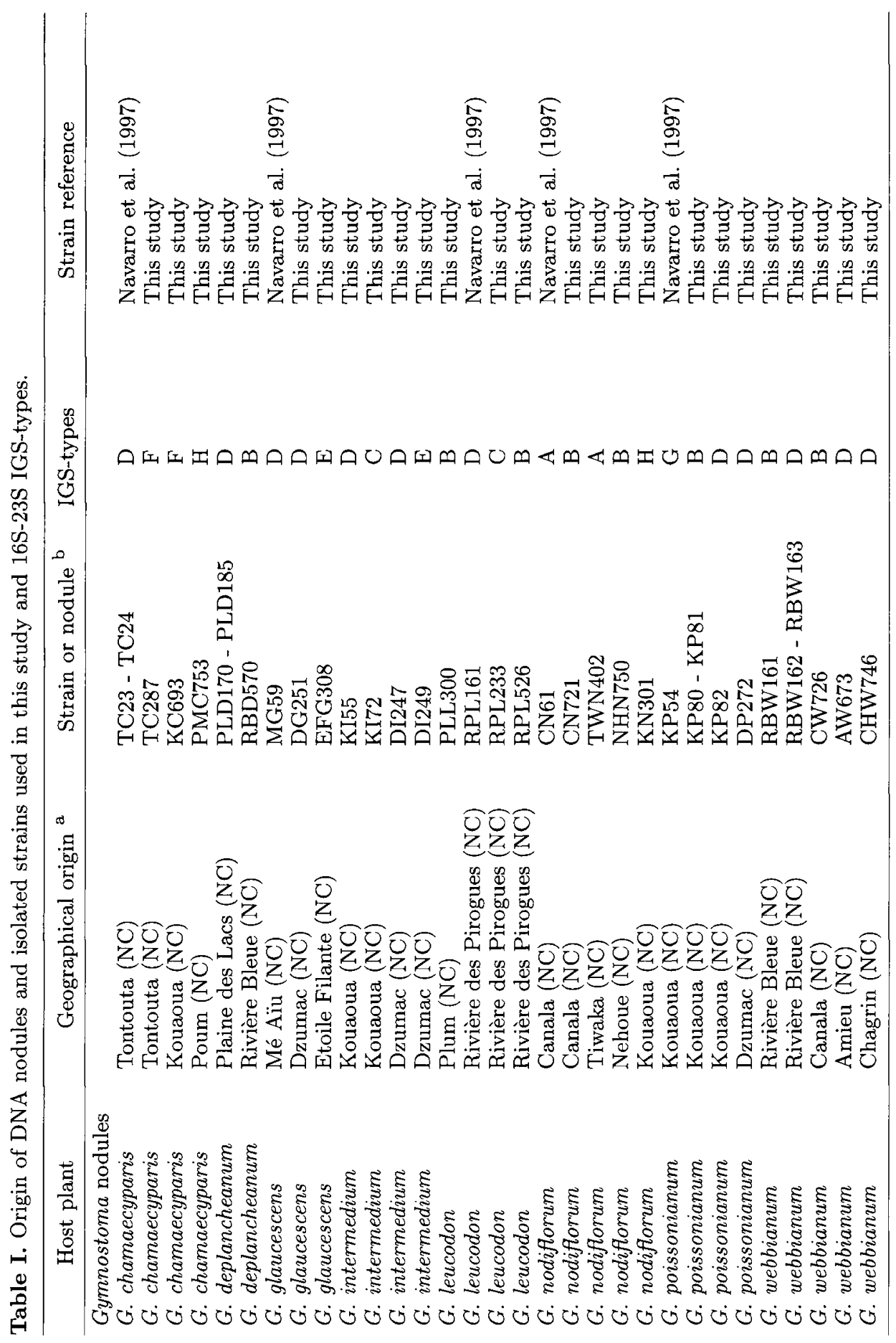




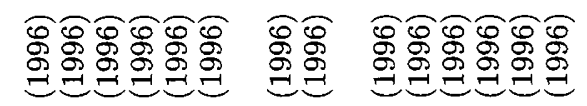

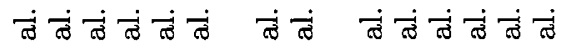

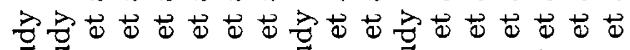

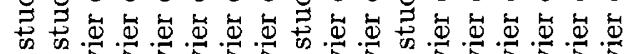

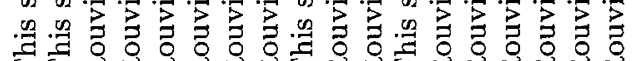

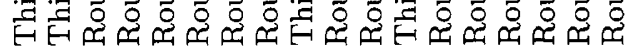

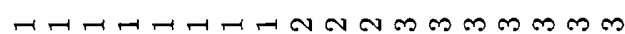

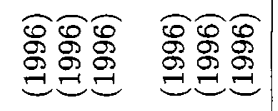
तं तं तं तं

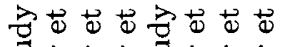

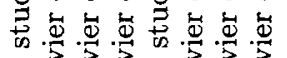

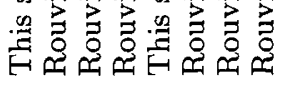

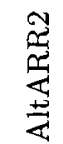

苞
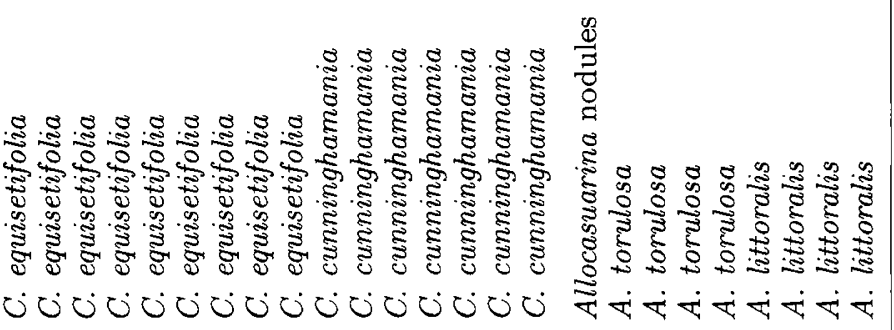


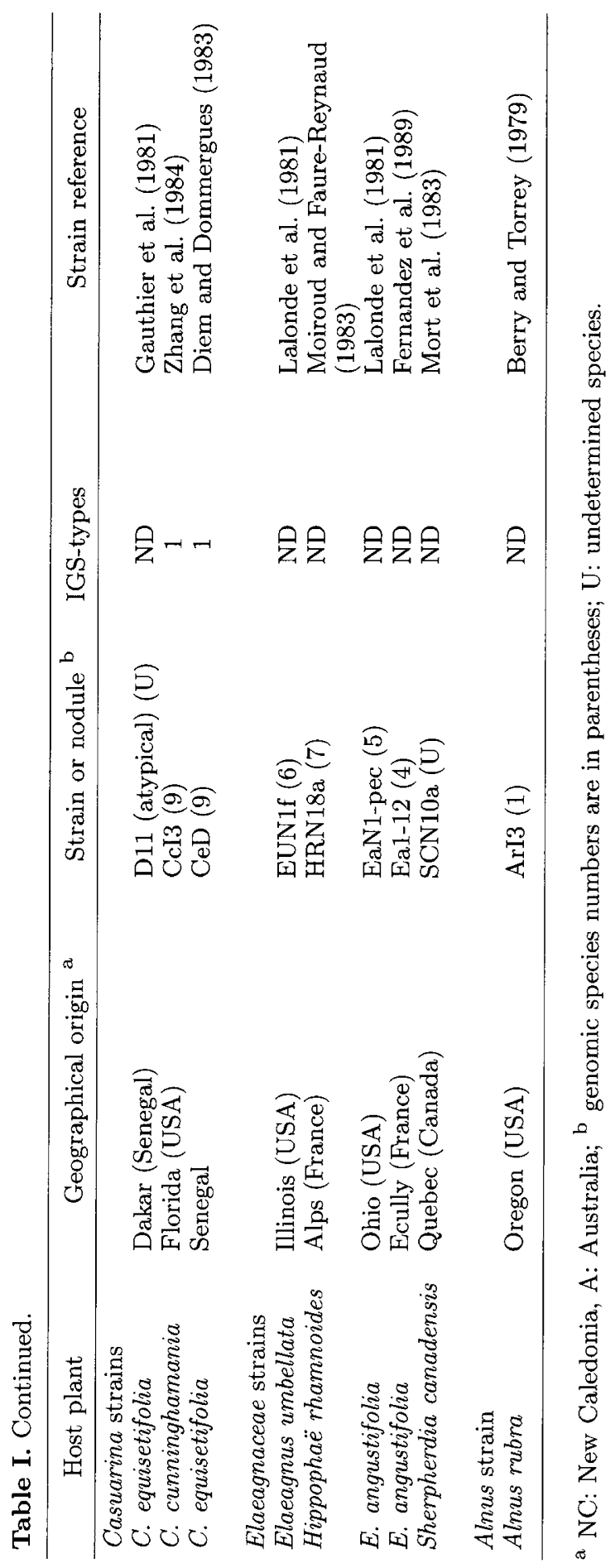




\subsection{Sequencing of IGS amplicons}

Before sequencing, the amplification reaction mix was purified by using Centricon-30 concentrators (Amicon-Grace Company, Epernon, France). The amplicons were sequenced using the Deaza G/A sequencing kit (Pharmacia Biotech SA, St-Quentin-Yvelines, France) and the direct DNA sequencing method described by Winship (1989). The fragments were sequenced in both directions. The sequences were determined for both strands.

\subsection{Data analysis}

The sequences were aligned with previously published sequences (Nalin et al., 1995; Navarro et al., 1997) using the multiple-alignment CLUSTA1V algorithm (Higgins and Sharp, 1988), with manual refinements in the noncoding regions. Distances were calculated according to Kimura's two-parameter model (Kimura, 1980) and phylogenetic analyses were made using neighbour-joining (N-J) (Saitou and Nei, 1987) and parsimony methods (Swofford, 1993). A bootstrap confidence analysis was performed with 1000 replicates to determine the reliability of the distance tree topologies obtained (Felsenstein, 1985). The resulting tree was drawn by using the N-J plot sofware (Perrière and Gouy, 1996).

\subsection{Amplicons restriction analysis}

Restriction endonuclease digestions were done with $15 \mu \mathrm{L}$ of PCR reaction mixture for each reaction. The endonucleases, $N c I 1, M s p I$, HaeIII (all from Boehringer Mannheim, Meylan, France) and $S c r F 1$ (Ozyme, Montigny Le Bretonneux, France) were used as specified by the manufacturers. Electrophoresis was carried out in a horizontal slab gel on a $4 \%$ (w/v) Nusieve (FMC, Rockland, ME, USA) agarose gel containing $0.5 \mu \mathrm{g} \mathrm{mL}^{-1}$ ethidium bromide, using TBE electrophoresis buffer ( $89 \mathrm{mM}$ Tris base, $89 \mathrm{mM}$ boric acid, $2 \mathrm{mM}$ EDTA). Gels were run at $4 \mathrm{~V} \mathrm{~cm}^{-1}$ for $3 \mathrm{~h}$ and photographed as described previously.

\section{RESULTS}

\subsection{Amplification}

The method used for extracting DNA from Casuarinaceae nodule lobes provided endophyte DNA that was pure enough to be efficiently amplified with the sets of primers tested (data not shown). A DNA fragment corresponding to the 16S-23S IGS was obtained for all the 55 templates tested, including DNA from isolates and from nonisolated strains (data not shown).

\subsection{Sequencing and comparison of the nifD-nifK intergenic spacer}

By using the sequencing strategy shown in figure 1 , a sequence that covers the $3^{\prime}$ end of nifD, the IGS and the beginning of nifK was obtained for all 11 DNAs studied and aligned with the published sequences (Nalin et al., 1995; Navarro et al., 1997) (figure 2). 


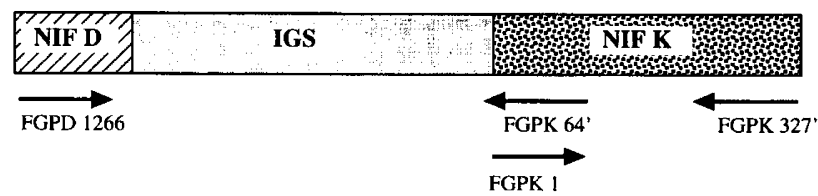

Figure 1. Sequencing strategy for the nifD-nifK intergenic spacers (IGS). The arrows show the direction of the sequencing reactions.

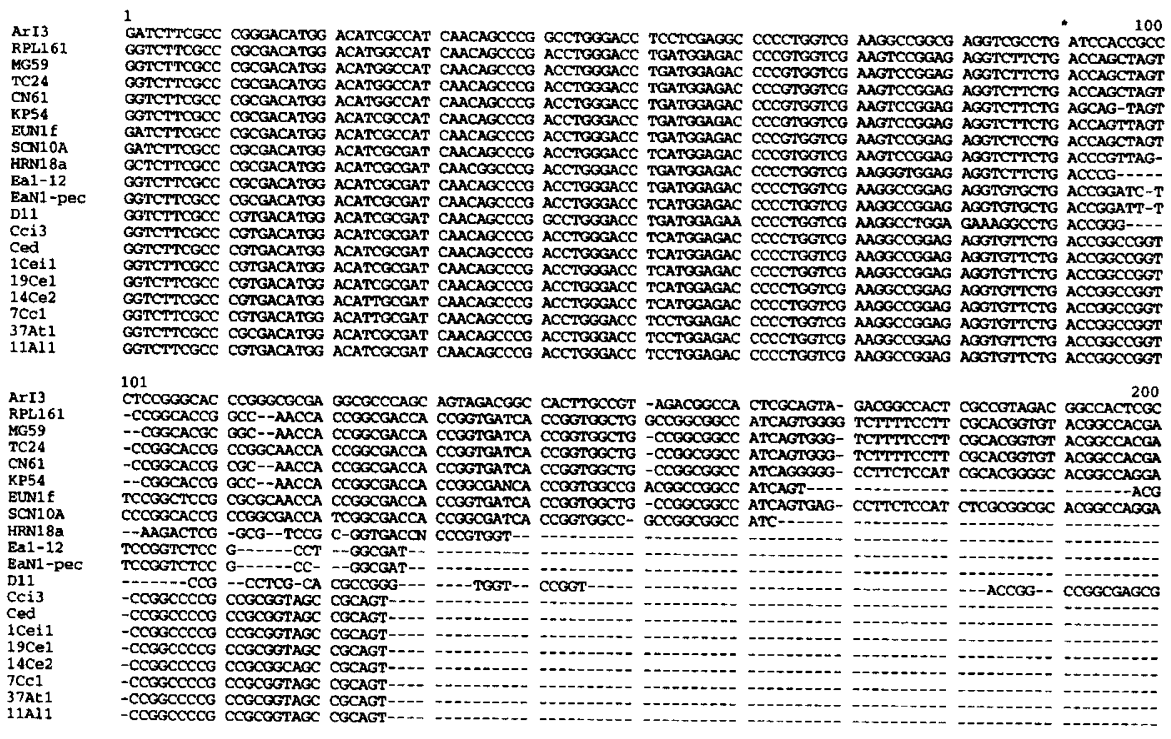

ArI3

RPL16

MG59

KN54

SCN1

SCN1OA

Ea1-12

EaN1-pec

D11

Ced

1Cei 1

$19 \mathrm{Ce} 1$

7Cc1

37At1

201

AGTAGACGGC CACTTGCAGT AGCTGACCAG TAGTTCATCC AGGCCTGGCC GAACCAGCCG CCAGCGACCC CGTGACCGGA GAAACGGTCG CTIGGCOCCTG ATGCCGTGAG CCCEAGTCGA CGACCGAAAA GGATGCCGTGAG CCCCGAGTCGA CGACCGAAAA GC-

A---CGTGAG CCCGAACTGG CGATGGAAA GG-

CA-GAAAGGC TGATGTTACG CGGTGCGTCG GT-

ATGCCGTCAG CCCGAGTCGG CGATGGAAAA GG

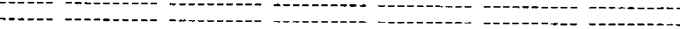

(1)

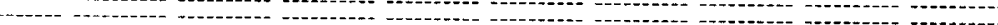

CCGGT-- - -

-

-

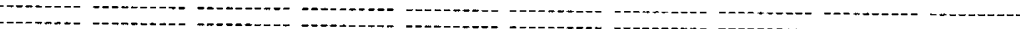

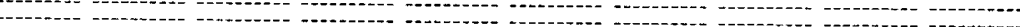

301

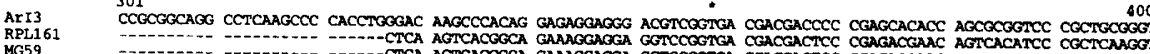

MG59

TC24

CN61

EUN1f

SON10A -

HRN18a -

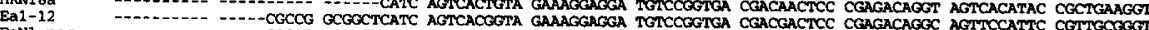

EaN1-pec -.-........-CGCCG GCGGC-CATC AGTCACGGTA GAAAGGAGGA TGTCCGGTGA CGACGACTCC GTAGACAGGC AGTTCCATTC CGTTGCGGGT

Cci3

Ced

1Ceil

$19 \mathrm{Ce} 1$

$14 \mathrm{Ce} 2$

37At1

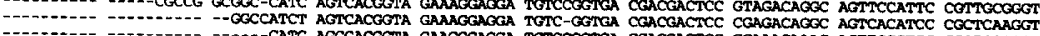

- -

(a) CATC AGCCACGGTA GAAGGGAGGA TGTCCGGTGA CGACGACTCC GGAAACAAAC AGTTCCGTCC CGCTGCGGG

作 CATC AGCCACGGTA GAAGGGAGGA TGTCCGGTGA CGACGACTCC GGAAACAAAC AGTTCCGTCC CGCTGCOGGT CATC AGCCACGGTA GAAGGGAOGA TGTCCGGTGA CGACGACTCC GGAAACAAAC AGTTCCGTCC CGCTGCGGG (1) CATC AGCCACGGTA GAAGGGAGGA TGTCCGGTGA CGACGACTCC GGAACAAAC AGTTCCGTCC CGCTGCGGAT 作

Figure 2. Alignment of the nifD-nifK intergenic spacer (IGS). The stop codon of $n i f \mathrm{D}$ and the start codon of nifK are marked by an asterisk. 
Ax13 401 1300 RPL161 CCTCAACCAC ACCGAGCTGT TCAAGGACGA GGTCTACACC AAGCAGTTCG AGACGAAGG CGAGTTCGAG AACGGTGCGA TCGACGCCGA GGTCAACCGG CCTCGACCAC ACCGAGCTGT TWAGGACA GOTCTACACC AAGCAGTTG AGACCAAGCG CGAGTTCGAG AACGGTGCGG ATCACGCCGA GGTCAACCGG CCTCGACCAC ACCGAGCTGT TCAAGGACGA GETCTACACC AAGCAGTTCG AGACCAAGCG CGAGTTCGAG AACGGTGCGG ATCACGCCGA GGTCAACCGG CCTCGACCAC ACCGAACTGT TCAAGGACGA GGTCTACACC AAGCAGTCG AGACCAAGGG CGAGTCGAG AACOGGCGG ATEACGCCGA GGTCAACCGG CCTCGACCAC ACCGAGCTET TCAAGGACGA GGTCTACACC AAGCAGTTCG AGACCAAGCG CGAGTTCGAG AACGGGGGG AMAGCGA GSTCAACCGG CCTCCACCAC AA CCTCGACCAC AGCGAGCTET TCAAGGACGA GGTCTACAGG AAGCAGTTCG AGACCAAGCG CGAGTTCGAG AACGGCGCCG ATGACGCCGA GGTCAACCGG GCTCGACCAC AACGACCTGT TCAAGGGCGA GGCCTACCAC AAGCAGTTCG AGGGAAAGAC CGAGTTCGAG AACGGCAGTG ACTCCGCCGA GGTTGCCCGC CCTCGACCAC AGCGAGCTGT TCAAGGACGA GGTCTACCAG AAGCAGTTCG AGGGCAAGAG CGAGTTCGAG AACGGCAGCG ACGCCGCCGA GGTGCAGCGG CTTCAACCAC AGCGAGCTGT TCAAGGACGA GGTCTACCAG AAGCAGTTCG AGGGCAAGCG CGAGTTCGAG AACGGCAGCG ACGCCGCCGA GGTCGCCCGG COTCGACAC AGCGAGCTGT TCAAGCACGA GGTCTACCAG AAGCAGT CCTCGACAC AGG CCTCGACCAC AGCGAGCTET TCAAGGACGA GGTCTACCAG GAGCAGTTCG AGGGCAAGCG CAATTTCGAG AACGCCACG ACGCCCCCGA GGTEGCCEG CCTCGACCAC AGCGAGCTGT TCAAGGACGA GGTCTACCAG AAGCAGTTCG AGGGCAAGCG CGAGTTCGAG AACGGCAGCG ACGCCGCCCA GGTCGCCCGG CCTCGACCAC AGCGAGCTGT TCAAGGACGA GGTCTACCAG AAGCAGTTCG AGGGCAAGCG CGAGTTCGAG AACGGCAGCG ACGCCGCCGA GGTCGCCCCG

501

GTCCTCGACT GGACCCGCGG GTGGGAGTAC CGGGAGAGA 544

GTCCTGGAGT GGACCCGTAC CTEGGAGTAC CGCGAGAAGA ACTT

GTCCTGGAGT GGACCCGTAC CTGGGAGTAC CGCGAGAAGA ACTY

GTCCTGGAGT GGACCCGTAC CTGGGAGTAC CGCGAGAAGA ACT

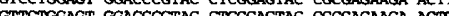

GTCCTGGAGT GCACCCGCAC CTGGGMGTAC CGCGAGAMGA ACT

GTCCTGGAGT GCACCCGCAC CTOGGMTAC CGCGAGAAGA ACTT

GTTCTGGAGT GGACCCGCGG CTGGGAGTAC CGCGAGAAGA ACT

GTCCTCGAGT GGACCCGCGG CTEGGAGTAC CGGGAGAMAA ACTT

GTCCTCGAGT GGACCCGCGG CTGGGAGTAC CGGGAGAAG ACTT

GTTCTCGAAT GCACCCGCGG CTEGGAGTAC CGGGAGAAGA ACTT

GTCCTGGAGT GGACCCGCGG CTGGGAGTAC CGGGAGAAGA ACT

GTCCTGGAGT GGACCCGCGG CTGGGAGTAC CGGGAGAAGA ACT

GTCCTGGAGT GGACCCGCGG CTGGGAGTAC CGGGAGAAGA ACTT

GTCCTGGAGT GGACCCGCGG CTGGGAGTAC CGGGAGAAGA ACT

GTCTGAGT GLACCGCG CTGGOAGTAC CGCGAGAAGA ACT

GTCCTCGAGT GGACCGCG CTOCOMTAC CGGGAGMAGA ACTT

GTCCTGGAGT GGACCCGCG CTGGGAGTAC CGGGAGAAGA ACTT

11A11

Figure 2. (Continued).

In the group of Casuarina/Allocasuarina-infective strains, up to six differences were observed (corresponding to 0.018 substitutions/site). In the group of Elaeagnaceae-infective strains, between 6 and 71 differences were observed (corresponding to 0.014-0.232 substitutions/site). The Alnus-infective strains exhibited between 84 and 175 differences with Casuarina-infective strain CcI3 and Gymnostoma microsymbiont MG59, respectively.

Two clusters were identified by using the distance matrix (table II) and the resulting phylogenetic tree (figure 3).

Cluster 1 is a very tight group that contains Casuarina and Allocasuarina microsymbionts. Two C. equisetifolia microsymbionts, 1 Cei1 and 19Ce1, have identical sequence with that of the reference Casuarina infective strains ( $t a-$ ble $I I)$. The remaining $C$. equisetifolia microsymbiont, $14 \mathrm{Ce} 2$, is very closely related to the $C$. cunninghamiana microsymbiont. This grouping was also detected by parsimony analysis. A. torulosa and $A$. littoralis microsymbionts form a group not confirmed by parsimony analysis. Nevertheless, 37At1 and 11Al1 sequences had a very low level of divergence (table $I I)$.

The Elaeagnaceae-infective strains form a broad group designated cluster 2. This coherent cluster ( $100 \%$ of the bootstrap replicates) was also detected by parsimony analysis. The level of sequence divergences was higher in this cluster than in cluster 1. Gymnostoma microsymbionts belonged to cluster 2. They form a coherent group ( $100 \%$ of the bootstrap replicates, parsimony analysis) with EUN1f and SCN10a.

\subsection{PCR/RFLP on 16S-23S IGS}

Using two restriction enzymes, IGS-types were determined (table $I I I$; figure 4). All reference Casuarina and Allocasuarina infective strains have 
E. Navarro et al.

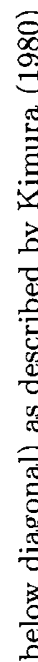

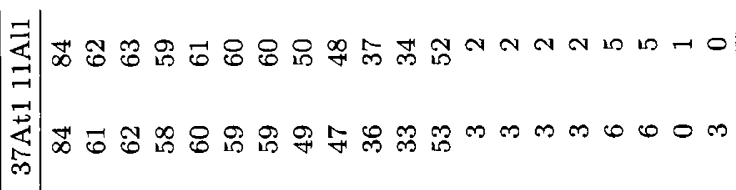

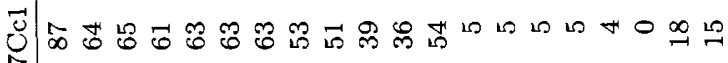

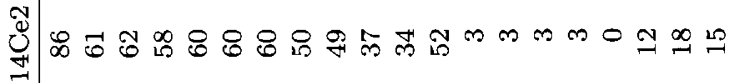

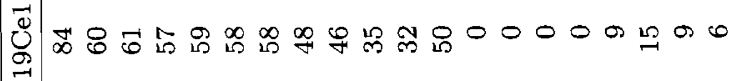
氙

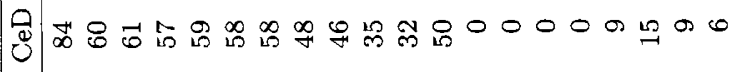

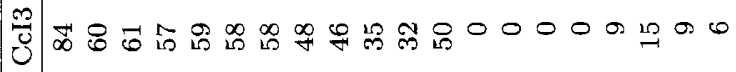

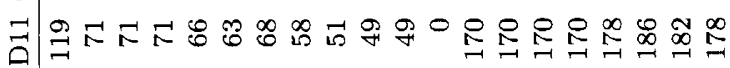
㿟 可

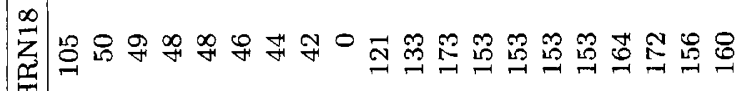
总

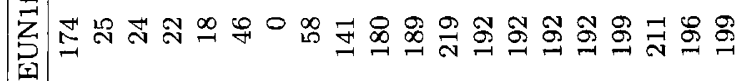

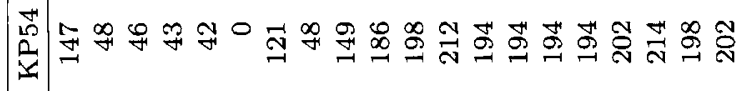

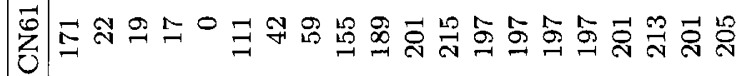
氙近へ 总 莯

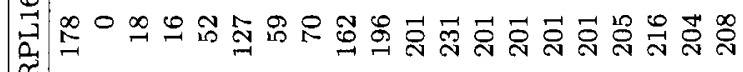

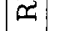

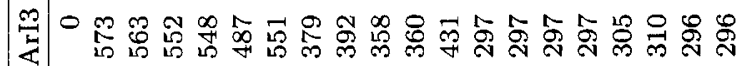




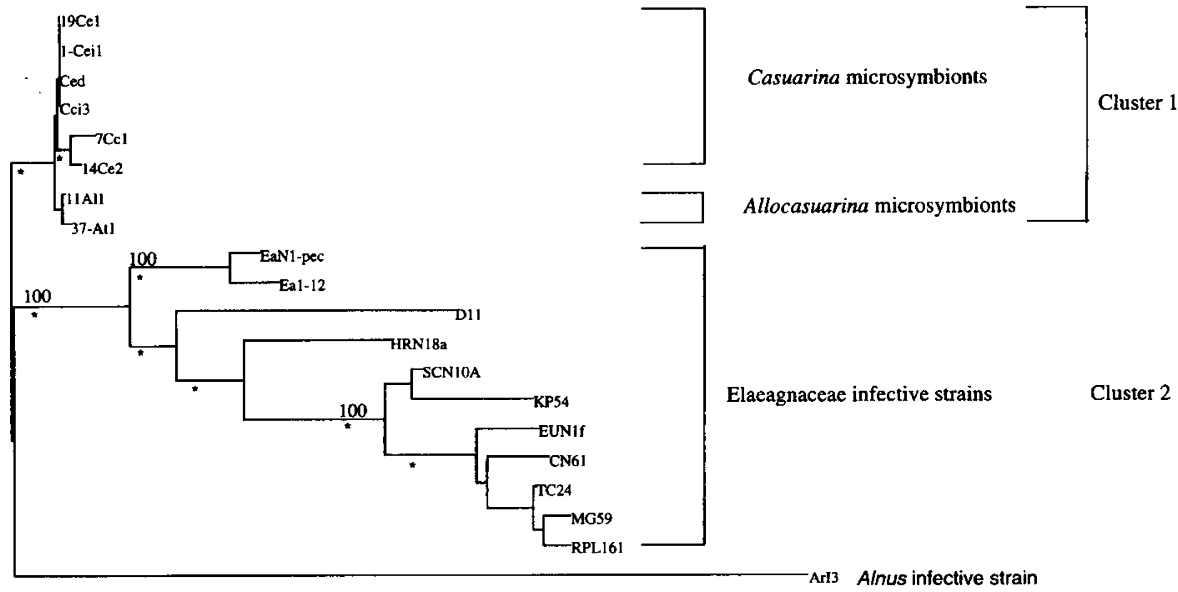

$\stackrel{0.028 \mathrm{~s} / \mathrm{s}}{1}$

Figure 3. Phylogenetic neighbour-joining tree based on nifD-nifK intergenic spacer sequences. The bars represent 0.028 substitutions/site. The numbers are the percentages of bootstrap replicates in which the cluster was found. An asterisk indicates that the group was found by parsimony analysis.

Table III. IGS-type determination.

\begin{tabular}{ccccc}
\hline IGS-types & \multicolumn{3}{c}{ Restriction patterns of the 16S-23S IGS } \\
\cline { 2 - 4 } & MspI & HaeIII & NcI1 & ScrF1 \\
\hline A & M1 & H1 & & \\
B & M1 & H2 & & \\
C & M2 & H1 & & \\
D & M2 & H3 & & \\
E & M3 & H3 & & \\
F & M3 & H4 & & \\
G & M4 & H1 & & \\
H & M5 & H5 & N1 & SF1 \\
1 & & & N2 & SF2 \\
2 & & & N3 & SF3 \\
3 & & & N1 & SF4 \\
4 & & & N4 & SF4 \\
5 & & & & \\
\hline
\end{tabular}

similar patterns and were grouped together (IGS-type 1), whereas the $\mathrm{Ca}$ suarina/Allocasuarina microsymbionts from Australia are distributed in five IGS-types (table I). C. equisetifolia microsymbionts belong to two IGS-types: 1 and 2 , the majority being in group 1 . IGS-type 3 contains $C$. cunninghamiana microsymbionts. Allocasuarina spp. microsymbionts belong to the remaining IGS-types. IGS-type 4 includes $A$. torulosa microsymbionts, whereas IGS-type 


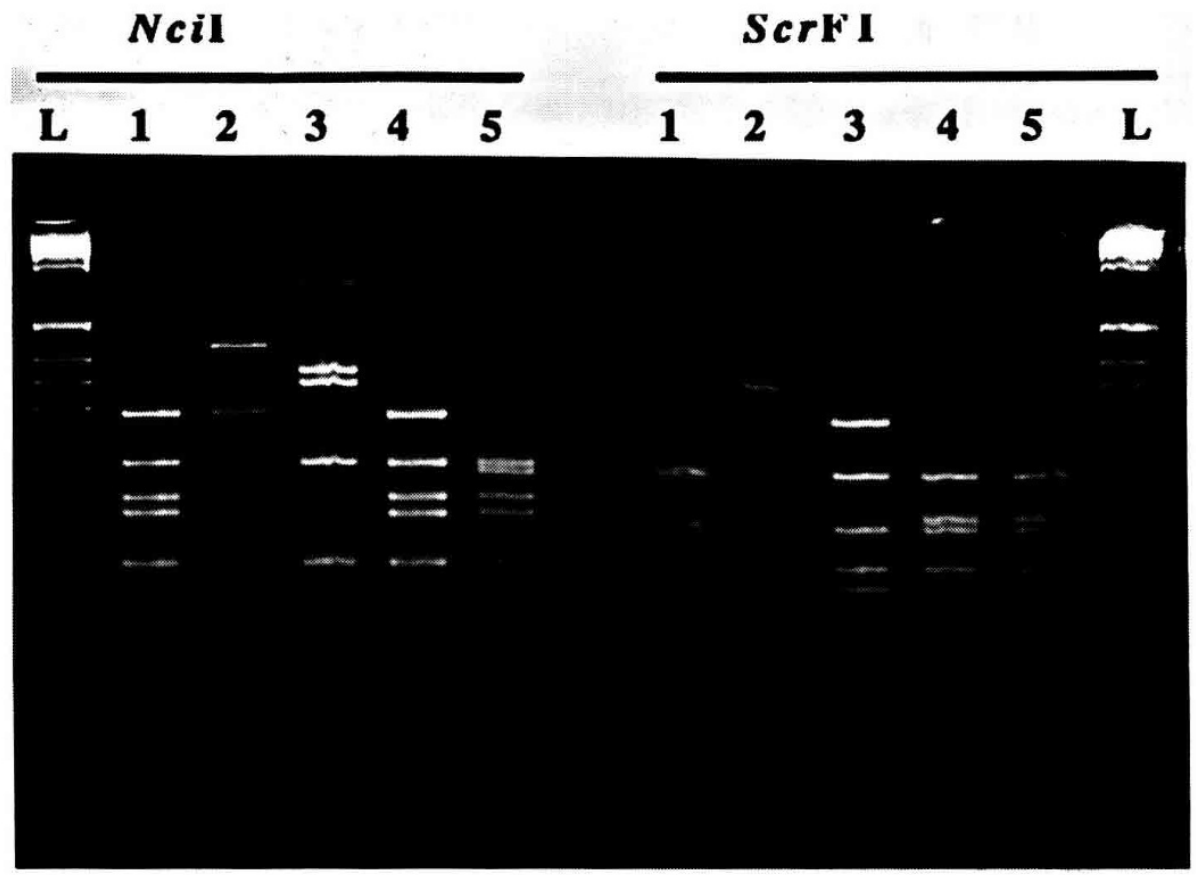

Figure 4. PCR/RFLP patterns of the 16S-23S intergenic spacer (IGS) after digestion with $N c i 1, S c r F 1$. Lanes 1 to 5, IGS-types 1 to 5; lane L, 1-kb ladder.

5 includes $A$. littoralis microsymbionts. The genotypic grouping of the Casuarina and Allocasuarina infective strains was consistently associated with the host plant species (table IVa).

The 35 Gymnostoma microsymbionts were distributed into eight IGS-types (table I). For each Gymnostoma species, microsymbionts belong to two or three IGS-types. Conversely, microsymbionts belonging to six IGS-types were associated with several Gymnostoma species. IGS-type D is the most promiscuous group, being found with seven of the eight Gymnostoma species tested.

The grouping of the strains according to molecular criteria was not related to the grouping based on the host plant species, since each species was found to have established naturally a symbiosis with microsymbionts classified in several IGS- types (table $I \mathrm{Vb}$ ).

\section{DISCUSSION}

Coevolution has been found in several host-pathogen systems (Futuyama, 1986) and in highly specific obligate mutualism such as endosymbiosis (Futuyama, 1986; Moran et al., 1993). Coevolution can be either loose or strict, but this must be confirmed by evidence for the congruence of the two partners' phylogenetic trees.

Comparative studies of the phylogenies of host plant and symbionts constitute a promising approach for the elucidation of the evolution of actinorhizal 
Table IV. Distribution of Frankia 16S-23S IGS-types as a function of Casuarinaceae species.

IVa. Casuarina and Allocasuarina species.

\begin{tabular}{llllll}
\hline & \multicolumn{5}{c}{ IGS-types } \\
\cline { 2 - 6 } Host plant & 1 & 2 & 3 & 4 & 5 \\
\hline C. equisetifolia & + & + & & & \\
C. cunninghamania & & & + & & \\
A. torulosa & & & & + & \\
A. littoralis & & & & & + \\
\hline
\end{tabular}

IVb. Gymnostoma species.

\begin{tabular}{lllllllll}
\hline & \multicolumn{7}{c}{ IGS-types } \\
\cline { 2 - 8 } Host plant & $\mathrm{A}$ & $\mathrm{B}$ & $\mathrm{C}$ & $\mathrm{D}$ & $\mathrm{E}$ & $\mathrm{F}$ & $\mathrm{G}$ & $\mathrm{H}$ \\
\hline G. chamaecyparis & & & & + & & + & & + \\
G. deplancheanum & & + & & + & & & & \\
G. glaucescens & & & & + & + & & & \\
G. intermedium & & & + & + & + & & & \\
G. leucodon & & + & + & + & & & & \\
G. nodiflorum & + & + & & & & & & + \\
G. poissonianum & & + & & + & & & + & + \\
G. webbianum & & + & + & + & & & & \\
\hline
\end{tabular}

symbiosis. Of the 21 dicotyledonous genera described as actinorhizal (Benson and Silvester, 1993), strains capable of fulfilling Koch's postulates or present as microsymbionts in 11 of these have had their $16 \mathrm{~S}$ determined and compared (Nick et al., 1992). This analysis has shown that the genus Frankia is coherent and that isolated strains infective on Casuarina are phyletically close to those infective on Alnus. Study of the plant phylogeny, on the other hand, has shown that Casuarina and the other Casuarinaceae genera Allocasuarina and Gymnostoma formed a phyletically coherent family in the Hammamelidae (Maggia and Bousquet, 1994). It was thus expected that the microsymbionts present in the nodules of these three genera would be phyletically close.

The present work on the nifD-nifK intergenic spacer has shown that, on the contrary, the nonisolated strains present in Gymnostoma nodules and Casuarina/Allocasuarina nodules belonged to different clusters. Casuarina/Allocasuarina microsymbionts form a tight group with a very low level of sequence divergence (figure 3 ; table II). The phylogenetic tree outlined in this cluster is similar to the trees obtained by PCR/RFLP analysis (figure 5). Gymnostoma microsymbionts were in the cluster of Elaeagnaceae-infective strains. Cross-inoculation studies have confirmed that Gymnostoma-infective strains are Elaeagnus-infective and not Casuarina-infective (Navarro et al., 1997).

Differences between Casuarina/Allocasuarina and Gymnostoma microsymbionts were confirmed by PCR/RFLP analysis of the 16S-23S intergenic spacer (table IV). Genetic diversity among Casuarina and Allocasuarina microsym- 


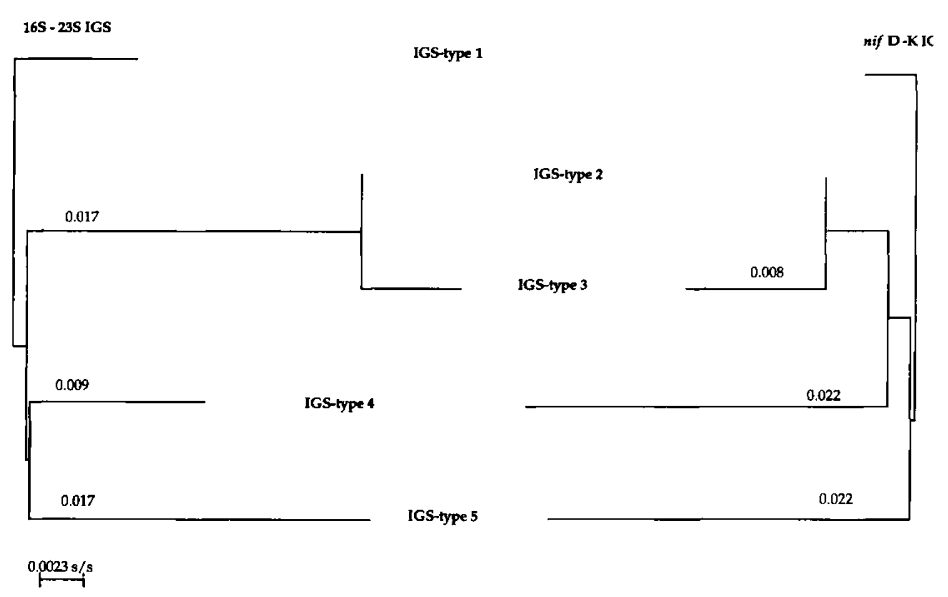

Figure 5. Dendrogram of genotypic relationship of intergenic spacer (IGS) sequences derived by PCR/RFLP analysis according to Rouvier (1995).

bionts seems to be host-species dependent. Cross-inoculation studies support this finding (Reddell and Bowen, 1985; Sellstedt, 1995). This differentiates this group from Gymnostoma microsymbionts for which no relation between genetic diversity and host species was observed. Identical results were obtained by cross-inoculation studies (Gauthier, personal communication).

These results mean that in the Casuarinaceae line of descent the host plants did not evolve gradually as proposed by Maggia and Bousquet (1994). These authors suggested that evolution of the symbiosis had been from a promiscuous ancestor identified as comparable to present-day Gymnostoma to the very restrictive descendant (Allocasuarina) with Casuarina in between. Instead, the most coherent scenario would be that an early split occurred in the evolution of Casuarinaceae, resulting in two distinct lines of descent. In each of them evolution of the symbiosis has occurred in two different ways. Evolution of the Casuarina/Allocasuarina symbiosis has proceeded towards a greater specificity and specialisation, and is presumably an example of coevolution. These host plants are in symbiosis with hard-to-isolate and slow-growing Frankia strains, suggesting that this symbiosis is becoming obligate. More saprophytic Frankia strains (Nalin et al., 1997), faster growing and easier to isolate, have established a nonspecific symbiotic association with Gymnostoma. No evolutionary relationships could be evidenced in this interaction. These hypotheses could be confirmed by comparing the phylogeny of the two symbiotic partners, using sequencing of host plant and microorganism DNA from the same nodule, from a larger sample of Casuarinaceae species.

\section{ACKNOWLEDGEMENTS}

Thanks are expressed to J. Briolay (Centre d'analyse moléculaire de la biodiversité) for technical assistance. 


\section{REFERENCES}

Benson D.R., Silvester W.B., Biology of Frankia strains, Actinomycete symbionts of Actinorhizal plants, Microbiol. Rev. 57 (1993) 293-319.

Berry A.M., Torrey J.G., Isolation and characterization in vivo and in vitro of an actinomycetous endophyte from Alnus rubra Bong, in: Gordon J.C., Wheeler C.T., Perry D.A. (Eds.), Symbiotic Nitrogen Fixation in the Management of Temperate Forests, Oregon State University, Corvallis, OR, 1979, pp. 69-83.

Bosco M., Fernandez M.P., Simonet P., Materassi R., Normand P., Evidence that some Frankia sp. strains are able to cross boundaries between Alnus and Elaeagnus host specificity groups, Appl. Environ. Microb. 58 (1992) 1569-1576.

Diem H.G., Dommergues Y., The isolation of Frankia from nodules of Casuarina, Can. J. Bot. 61 (1983) 2822-2825.

Diem H.G., Dommergues Y., Current and potential uses and management of Casuarinaceae in the tropics and subtropics, in: Schwintzer C.R., Tedpkema J.D. (Eds.), The Biology of Frankia and Actinorhizal Plants, Academic Press, Inc., New York, 1990, pp. 317-342.

Diem H.G., Duhoux E., Simonet P., Dommergues Y., Actinorhizal symbiosis biotechnology: the present and the future, in: Durand G., Bodichon L., Florent J. (Eds.), Proceedings of the 8th International Biotechnology Symposium, Société française de microbiologie, Paris, 1988, pp. 984-995.

Felsenstein J., Confidence limits on phylogenies: an approach using the bootstrap, Evolution 39 (1985) 783-791.

Fernandez M.P., Meugnier H., Grimont P.A.D., Bardin R., Deoxyribonucleic acid relatedness among members of the genus Frankia, Int. J. Syst. Bacteriol. 39 (1989) 424-429.

Futuyama D.J., The evolution of interactions among species, in: Davis A., Vesely J. (Eds.), Evolutionary Biology, Sinauer Associates, Inc., Sunderland, MA, 1986, pp. 482-504.

Gauthier D., Diem H.G., Dommergues Y., Infectivité et effectivité des souches de Frankia isolées de nodules de Casuarina equisetifolia et Hippophae rhamnoides, C.R. Acad. Sci. 293 (1981) 489-491.

Higgins D.G., Sharp P.M., CLUSTAL: a package for performing multiple sequence alignments on a microcomputer, Gene 73 (1998) 237-244.

Jamann S., Fernandez M.P., Normand P., Typing method for $\mathrm{N}_{2}$-fixing bacteria based on PCR-RFLP - application to the characterisation of Frankia strains, Mol. Ecol. 2 (1993) 17-26.

Johnson L.A.S., Wilson K.L., Casuarinaceae: a synopsis, in: Crane P.R., Blackmore S. (Eds.), Evaluation, Systematics and Fossil History of the Hamamelidae, vol. 2: Higher Hamamelidae, Systematics Association, Claredon Press, London, special vol. $40 \mathrm{~B}, 1989$, pp. $67-188$.

Kimura M., A simple method for estimating evolutionary rates of base substitutions through comparative studies of nucleotide sequences, J. Mol. Evol. 16 (1980) 111-120.

Lalonde M., Calvert H.E., Pine S., Isolation and use of Frankia strains in actinorhizae formation, in: Gibson A.H., Newton W.E. (Eds.), Current Perspectives in Nitrogen Fixation, Australian Academy of Science, Canberra, 1981, pp. 296-299.

Maggia L., Bousquet J., Molecular phylogeny of the actinorhizal Hamamelidae and relationships with host promiscuity towards Frankia, Mol. Ecol. 3 (1994) 459467.

Moiroud A., Faure-Reynaud M., Influences de quelques herbicides à large spectre sur la croissance et l'infectivité de cultures pures de Frankia, Plant Soil 74 (1983) 133-136. 
Moran N.A., Muson M.A., Baumann P., Ishikawa H.I., A molecular clock in endosymbiotic bacteria is calibrated using the insect hosts, Proc. R. Soc. Lond. [Biol.] 253 (1993) 167-171.

Mort A., Normand P., Lalonde M., 2-O-methyl-D-mannose, a key sugar in the taxonomy of Frankia, Can. J. Microbiol. 29 (1983) 993-1002.

Nalin R., Normand P., Domenach A.-M., Characterization of a Frankia community in a soil column, Physiol. Plant. 99 (1997) 732-738.

Nalin R., Domenach A.-M., Normand P., Characterization of an intergenic spacer between nifD and nifK in Frankia, Mol. Ecol. 4 (1995) 483-491.

Navarro E., Simonet P., Normand P., Bardin R., Characterization of natural population of Nitrobacter spp. using PCR/RFLP analysis of the ribosomal intergenic spacer, Arch. Microbiol. 157 (1992) 107-115.

Navarro E., Nalin R., Gauthier D., Normand P., The nodular microsymibionts of Gymnostoma spp. are Elaeagnus-infective strains, Appl. Environ. Microb. 63 (1997) 1610-1616.

Nazaret S., Cournoyer B., Normand P., Simonet P., Phylogenetic relationships among Frankia genomic species determined by use of amplified 16S rDNA sequences, J. Bacteriol. 173 (1991) 4072-4078.

Nick G., Paget E., Simonet P., Moiroud A., Normand P., The nodular endophytes of Coriara spp. form a distinct lineage within the genus Frankia, Mol. Ecol. 1 (1992) 175-181.

Perrière G., Gouy M., WWW-Query: an on-line retrieval system for biological sequence banks, Biochimie 78 (1996) 364-369.

Ponsonnet C., Nesme X., Identification of Agrobacterium strains by PCR-RFLP analysis of pTi and chromosomal regions, Arch. Microbiol. 161 (1994) 300-309.

Racette S., Torrey J.G., The isolation, culture and infectivity of a Frankia strain from Gymnostoma papuanum (Casuarinaceae), Plant Soil 118 (1989) 165-170.

Reddell P., Bowen G.D., Do single nodules of Casuarinaceae contain more than one Frankia strain? Plant Soil 88 (1985) 275-279.

Rouvier C., Caractérisation génétique de Frankia nodulant les Casuarinacées : influence de la plante-hôte et de sa zone d'origine, l'Australie, thesis, Université Lyon I, France, 1995.

Rouvier C., Nazaret S., Fernandez M.P., Picard B., Simonet P., Normand P., rrn and nif intergenic spacers and isoenzyme patterns as tools to characterize Casuarina-infective Frankia strains, Acta Oecol. 13 (1992) 487-495.

Rouvier C., Prin Y., Reddell P., Normand P., Simonet P., Genetic diversity among Frankia strains nodulating members of the family Casuarinaceae in Australia revealed by PCR and restriction fragment length polymorphism analysis with crushed root nodules, Appl. Environ. Microb. 62 (1996) 979-985.

Saitou R.R., Nei M., A Neighbor-Joining method: a new method for reconstructing phylogenetic trees, Mol. Biol. Evol. 44 (1987) 406-425.

Savouré A., Lim G., Characterization of an infective Frankia (ISU 0224887) isolated from nodules of Gymnostoma sumatranum, Plant Soil 131 (1991) 21-27.

Sellstedt A., Specificity and effectivity in nodulation by Frankia on southern hemisphere actinorhiza, FEMS Microbiol. Lett. 125 (1995) 231-236.

Swofford D.L., PAUP - phylogenetic analysis using parsimony, version 3.1, Illinois Natural History Survey, Champaign, IL, 1993.

Winship P.R., An improved method for directly sequencing PCR amplified material using dimethyl sulfoxide, Nucleic Acids Res. 17 (1989) 1266.

Zhang Z., Lopez M.F., Torrey J.G., A comparison of cultural characteristics and infectivity of Frankia isolates from root nodules of Casuarina species, Plant Soil 78 (1984) 79-90. 